\title{
Thunderstorm Asthma: A Critical Appraisal Based on Clinical Practice
}

Caminati $\mathrm{M}^{1}$, Senna $\mathrm{G}^{1}$, Vianello $\mathrm{A}^{2}$, Ricci $\mathrm{G}^{3}$, Bellamoli $\mathrm{R}^{1}$, Longhi $\mathrm{S}^{1}$, Crivellaro $\mathrm{M}^{4}$, Marcer $\mathrm{G}^{4}$, Monai $\mathrm{M}^{5}$, Passalacqua $\mathrm{G}^{6}$ ${ }^{1}$ Asthma Center and Allergy Unit, Verona University and General Hospital, Verona, Italy

${ }^{2}$ Respiratory Pathophysiology Division, University-City Hospital of Padua, Padua, Italy

${ }^{3}$ Emergency Department, Clinical Toxicology Unit, Verona University and General Hospital, Verona, Italy

${ }^{4}$ Allergy Service, Department of Medicine and Public Health, University of Padua, Padua, Italy

${ }^{5}$ Meteorological Service, Veneto Regional Agency for Environment Protection and Prevention, Padua, Italy

${ }^{6}$ Allergy and Respiratory Diseases, Policlinico San Martino, University of Genoa, Italy

J Investig Allergol Clin Immunol 2018; Vol. 28(4): 273-275 doi: 10.18176/jiaci.0259

Key words: Thunderstorm-related asthma. Asthma exacerbations. Meteorological factors and asthma. Fatal asthma.

Palabras clave: Asma relacionada con las tormentas. Exacerbaciones de asma. Factores meteorológicos y asma. Asma grave.

Thunderstorm asthma can be defined as an asthma outbreak characterized by a sudden increase in visits to the family physician, emergency department (ED), and/or hospitalizations due to asthma exacerbations concomitant with thunderstorms [1]. More than 8500 severe asthma attacks and 9 fatal cases were recently reported during a storm in Melbourne, Australia. Previous asthma epidemics related to thunderstorms have been described in Australia and the United Kingdom [2]. High grass pollen and outdoor mold levels, strong winds, and heavy rains are usually associated with thunderstorm asthma [3,4], although the exact mechanisms linking asthma and thunderstorms remain unclear. One possible explanation is the increased bioavailability of pauci-micronic particles of pollens, which are produced via osmotic shock and can easily reach the lower bronchial airways. Alternatively, the intense electrical fields that develop during thunderstorms could be responsible for the fragmentation of pollen grains into micronic particles [2]. Furthermore, gusty winds during the thunderstorm can mechanically increase the release of airborne allergens into the environment [2]. Climate change has led to an increase in the duration of pollen seasons, with higher pollen counts, and in the number of storms with and without lightning [2-6]. However, thunderstorm asthma remains an uncommon phenomenon. Epidemics of thunderstorm asthma could be the tip of the iceberg, and local minor episodes might be undervalued or go unrecognized, as recently reported $[7,8]$.

In the present study, we aimed to investigate the potential relationship between the number of admissions to the ED due to asthma attacks and the occurrence of thunderstorms within 
Table. Emergency Department Admissions for Asthma According to the Number of Thunderstorm-Free and Thunderstorm Days

\begin{tabular}{lcrcc}
\hline & No. & ER Admissions & Mean Daily Admissions & $P$ Value \\
\hline Thunderstorm-free days & 1011 & 784 & 0.77 \\
Thunderstorm days & 273 & 232 & 0.85 & 0.83 \\
Thunderstorm day & 151 & & 126 & 0.87 \\
$\quad$ After thunderstorm & 122 & 106 & 1016 & 0.79 \\
Total & 1284 & & 116 \\
\hline
\end{tabular}

ER, Emergency Room

a specific area of northeast Italy. Our study was based on data collected by the Meteorological Service of Veneto Regional Agency for Environmental Protection and Prevention (www. arpa.veneto.it) and by 2 large EDs in the northeast of Italy.

We reviewed all patients attending the ED for an asthma attack who were admitted to the Hospitals of Padua (220 000 inhabitants) and Verona (250 000 inhabitants), the 2 main emergency centers in our geographic area. All admissions were considered independently of the clinical severity of the exacerbations. Thunderstorms and admissions to the ED were recorded between April 1 and September 30 for 3 consecutive years (2013-2015). Admissions to the ED for an asthma attack during the days immediately before, during, and after a thunderstorm were reviewed and compared. Data were analyzed using the chi-square test, with a significance level of $5 \%$. Outlier values were identified by means of the $3 \sigma$ rule. Data were analyzed using $\mathrm{R}$.

Overall, no significant differences were found between Verona and Padua for admissions to the ED for asthma attack and number of thunderstorm events per year during the study period (data not shown). Therefore, the cumulative data of the 2 EDs were analyzed together. The number of daily admissions to the ED for acute asthma episodes did not differ between thunderstorm-free days and thunderstorm days, which included the days of the thunderstorm plus the days after the thunderstorm (possible delayed effect). Furthermore, a day-byday review of asthma-related admissions to the ED failed to identify any differences in the average values specifically from the days surrounding the thunderstorm. The Table summarizes the distribution of thunderstorm days and the number of ER admissions in the above-mentioned timeframe.

These data would suggest the lack of an overall association between thunderstorms and asthma exacerbations. Thus, thunderstorm asthma might be considered, at least in the northeast area of Italy, an unusual phenomenon that requires the coexistence of various meteorological and aerobiological determinants, some of which are still unknown. These include different patterns of allergen release, which may play a critical role depending on the specific geographical areas [9]. However, despite a significant increase in grass pollen levels in the last 5 years in our area, no significant parallel increase in admissions was recorded during the pollen season in the days surrounding a thunderstorm in comparison with thunderstormfree days. Furthermore, molds have been reported to be a relevant determinant of thunderstorm asthma. In this context, we recently reported 17 cases of fatal asthma in the same geographical area and in the same period [10]. These included 6 patients who were allergic to Alternaria species and died on days with a high concentration of this mold. However, no thunderstorm was recorded at the time.

Even though our findings did not show an association between thunderstorms and outbreaks of asthma exacerbation in the form of admissions to the ED in our geographic area, questioning the phenomenon of thunderstorm asthma is not our aim. On the contrary, we wanted to explore a potentially undervalued or unrecognized event. However, as mentioned above, thunderstorm could be the result of a complex interaction between several determinants; therefore, are findings cannot be generalized. Our observations show that, although many fascinating and convincing hypotheses have been proposed, thunderstorm asthma still remains a poorly defined asthma phenotype owing to its rare occurrence and to conflicting demonstrations of cause-effect. In addition, multiple local determinants such as geographical, meteorological, and aerobiological factors intervene simultaneously, so that providing general recommendations remains difficult. Although prevention is a priority within the education of asthmatic patients, unmet needs should be addressed in order to avoid unjustified alarmism.

\section{Funding}

The authors declare that no funding was received for this study.

\section{Conflicts of Interest}

The authors declare that they have no conflicts of interest.

\section{References}

1. D'Amato G, Annesi-Maesano I, Molino A, Vitale C, D'Amato M. Thunderstorm-related asthma attacks. J Allergy Clin Immunol. 2017;139:1786-7.

2. D'Amato G, Holgate S, Pawankar R, Ledford DK, Cecchi L, AlAhmad $\mathrm{M}$, et al. Metereological conditions, climate change, new emerging factors and asthma and related disorders. A statement of World Allergy Organization. World Allergy Organ J. 2015;8:25.

3. Taylor PE, Flagan RC, Valenta R, Glovsky MM. Release of allergen respirable in aerosols: a link between grass pollen and asthma. J Allergy Clin Immunol. 2002;109:51-6. 
4. Grinn-Gofron A, Strzelczak A. Changes in concentration of Alternaria and Cladosporium spores during summer storms. Int J Biometeorol. 2013;57:759-68.

5. Ariano R, Canonica GW, Passalacqua G. Possible role of climate changes in variations in pollen seasons and allergic sensitizations during 27 years. Ann Allergy Asthma Immunol. 2010;104:215-22.

6. D'Amato M, Cecchi L, Annesi-Maesano I, D'Amato G. News on Climate change, air pollution and allergic trigger factors of asthma. J Investig Allergol Clin Immunol. 2018;17:0. [Epub ahead of print]

7. Marks GB, Colquhoun JR, Girgis ST, Koski MH, Treloar AB, Hansen $P$, et al. Thunderstorm outflow preceding epidemics of asthma during spring and summer. Thorax. 2001;56:468-71.

8. Losappio L, Heffler E, Contento F, Cannito C, Rolla G. Thunderstorm-related asthma epidemic owing to Olea Europea pollen sensitization. Allergy. 2011;66:1510-1.

9. Buters J, Prank M, Sofiev M, Pusch G, Albertini R, AnnesiMaesano I, et al. Variation of the group 5 grass pollen allergen content of airborne pollen in relation to geographic location and time in season. J Allergy Clin Immunol. 2015;136:87-95.

10. Vianello A, Caminati M, Crivellaro MA, El Mazloum R, Sneghi R, Schiappoli M, et al. Fatal asthma: still an epidemic? World Allergy Organ J. 2016:9:42.

Manuscript received January 13, 2018; accepted for publication March 28, 2018.

Marco Caminati

Asthma Center and Allergy Unit Verona University and General Hospital

Piazzale Scuro 10

37134 Verona, Italy 